Article

\title{
Development of a Model Test System for a Piston Ring/Cylinder Liner-Contact with Focus on Near-to-Application Seizure Behaviour
}

\author{
Michael Pusterhofer*(D), Florian Summer ${ }^{\circledR}$, Daniel Wuketich and Florian Grün $(\mathbb{D}$ \\ Mechanical Engineering, Montanuniversität Leoben, 8700 Leoben, Austria; \\ florian.summer@unileoben.ac.at (F.S.); daniel.wuketich@unileoben.ac.at (D.W.); \\ florian.gruen@unileoben.ac.at (F.G.) \\ * Correspondence: michael.pusterhofer@unileoben.ac.at
}

Received: 28 October 2019; Accepted: 16 November 2019; Published: 22 November 2019

check for updates

\begin{abstract}
Physical simulations of tribo contacts in internal combustion engines can act as a supporting tool to match upcoming guidelines and emission restrictions. In particular, the scuffing resistance of the contact between the piston ring and cylinder liner suffers under decreasing oil viscosity and limitation of antiwear additives. This paper aims to provide an experimental method to simulate the scuffing of the piston ring/cylinder liner-contact and to validate this method with real engine parts and the literature from engine tests. The experimental methodology uses a linear tribometer TE77 to test specimens from original piston rings and liners under reciprocating motion. Additionally, the ring specimen is given the opportunity to perform secondary movements (ring twisting, ring turning) and to run under deficient lubrication conditions similar to the engine. A specially designed test strategy enables the reproducible creation of seizure of the tribosystem. The seizure resistance of two engine oils, tested for validation, correlates with the known engine performance. Therefore, the model test system can be seen as a reproducible tool for simulating seizure of a ring/liner-system, showing similar trends and wear mechanisms as in an engine. Surface analysis depicts similarities between the scuffed surfaces of an engine and the model and discusses the origin of seizure based on the model specimens together with the relevant literature.
\end{abstract}

Keywords: piston ring; cylinder liner; scuffing; seizure; model test; physical simulation

\section{Introduction}

Because of the continuing trend towards a reduction in lubricant viscosity $[1,2]$ and a reduction in crucial antiwear additive ingredients, piston groups in future engines are facing a higher risk of seizure and failure during operation. Simulating the conditions in such future engines with new lubricants and material combinations and providing a low-cost alternative to engine tests can be done via laboratory model tests.

Ring on liner model tests are known tools for benchmarking materials and lubricants in terms of friction assessment [3,4] and seizure resistance [5-7]. To draw the right conclusions, a proper transfer of results regarding the application of interest has to be considered within the methodology development.

Basic investigations about chemical interaction of lubricants and sliding materials can be carried out by model tests with simple geometries [8,9]. However, these test configurations have a limited potential to depict the application's damage mechanisms and tribosystem rankings. Simulating the conditions as accurately as possible, in order to provide more significant results, is the goal of what is called a physical simulation [10]. Manufacturing specimens out of original parts and using the original running surface is the closest to a real application [11-15], but can be difficult in terms of manufacturing 
and mounting. Producing artificial specimens with the basic properties of the real engine components is therefore a common procedure [16,17], which helps to avoid issues such as misalignments.

Beside a close-to-application specimen production, details of the test rig and the test procedure can be crucial for the correct transfer of the application results. For example Biberger et al. implement a lubrication system with a very low flow rate for their ring/liner model tester, to match the deficient lubrication situation of the top piston ring [18]. The heating of the piston group with combustion gases is simulated by Johansson et al. with a heat gun combined with a water cooling system for the liner [3].

The seizure process of the piston ring/cylinder liner-contact is a well investigated phenomenon, but is still not fully understood. From the damage analysis of fired engine components (such as published in [19]) to the evaluation of engine operation parameters [20,21], the basic nature of piston ring seizure has been investigated using model test systems over the years. Depending on the exact material and lubricant combination, the mechanism and evolution of seizure and scuffing could be determined. Examples of failure mechanisms for the ring/liner-contact are given in Section 4.

Investigating the seizure resistance, as a very sensitive value of a tribo system, requires a high level of physical simulation method to provide reproducible results. The test rig design and experimental methodology are significant factors which affect this goal. This work shows that seizure results obtained from the presented methodology are in accordance to well-known engine test results.

\section{Methodical Approach}

\subsection{Boundary Conditions and Materials}

The tribological conditions for the top piston ring/cylinder liner-contact in a heavy duty diesel (HDD) engine with a displacement of more than $10 \mathrm{~L}$ were reproduced, using a physical simulation approach (see Figure 1). To match the conditions as accurately as possible, original materials, a deficient lubrication system and application-near input parameters were chosen (overview in Table 1).

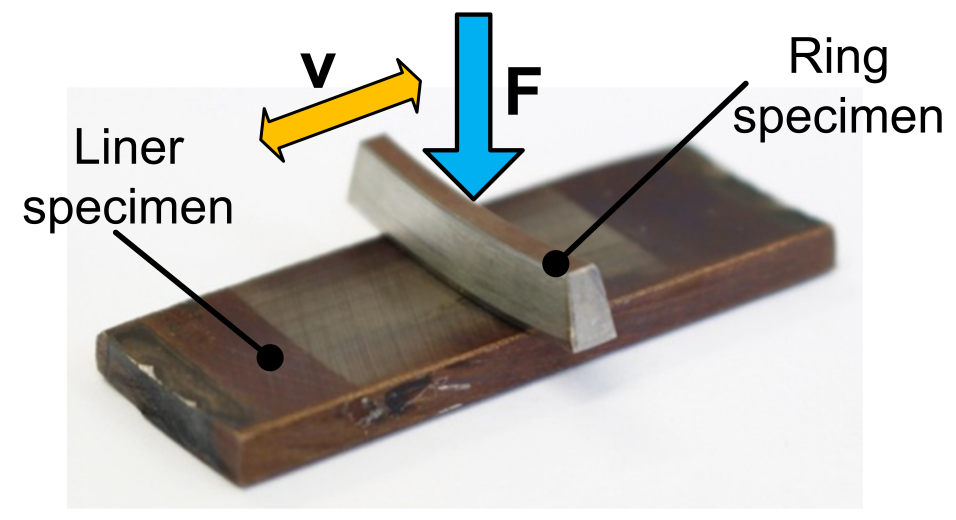

Figure 1. Model test configuration.

The relative velocity of a combustion engine with a maximum of several metre per second cannot be matched by a laboratory-based model test system. The used TE77 tribometer provides a maximum speed of $1.5 \mathrm{~m} / \mathrm{s}$ which is sufficient for the simulation of the area around top dead centre (TDC). In this area, a significant amount of mixed friction can occur, which is critical for the seizure of the system.

Temperatures can vary between different engines and different operation points. MAHLE provides temperature informations for pistons of diesel engines in a range $200-300{ }^{\circ} \mathrm{C}$ for the top piston groove [22]. Zima published temperature measurements of a diesel railway engine liner, measured at $3.3 \mathrm{~mm}$ under the surface of TDC, which are around $150{ }^{\circ} \mathrm{C}$ [23]. For the model test system, the temperature is controlled on the liner side, $\approx 1.7 \mathrm{~mm}$ under the running surface (see Figure 2). In accordance with the provided engine test data, a system temperature for the model tests of $160^{\circ} \mathrm{C}$ was chosen. 
Table 1. Boundary conditions.

\begin{tabular}{ccc}
\hline Component/Parameter & Used in Application & Used in Model \\
\hline Liner & Honed grey cast iron & Original \\
Piston ring & Coated chromium-steel & Original with coating removed \\
Lubricant & Fully formulated engine oils & Original engine oils \\
Lubrication & Deficient $($ due to oil scaper ring) & Min. drop lubrication $(0.04 \mathrm{~mL} / \mathrm{min})$ \\
Relative velocity & Max. $5-15 \mathrm{~m} / \mathrm{s}$ according to [24] & Max. $1.5 \mathrm{~m} / \mathrm{s}$ \\
Temperature & $200-300{ }^{\circ} \mathrm{C}$ at top piston groove $[22]$ & $160{ }^{\circ} \mathrm{C}$ system temperature \\
Contact pressure & $17 \mathrm{MPa}$ peak according to [25] & $5 \mathrm{MPa}$ constant for running-in \\
\hline
\end{tabular}

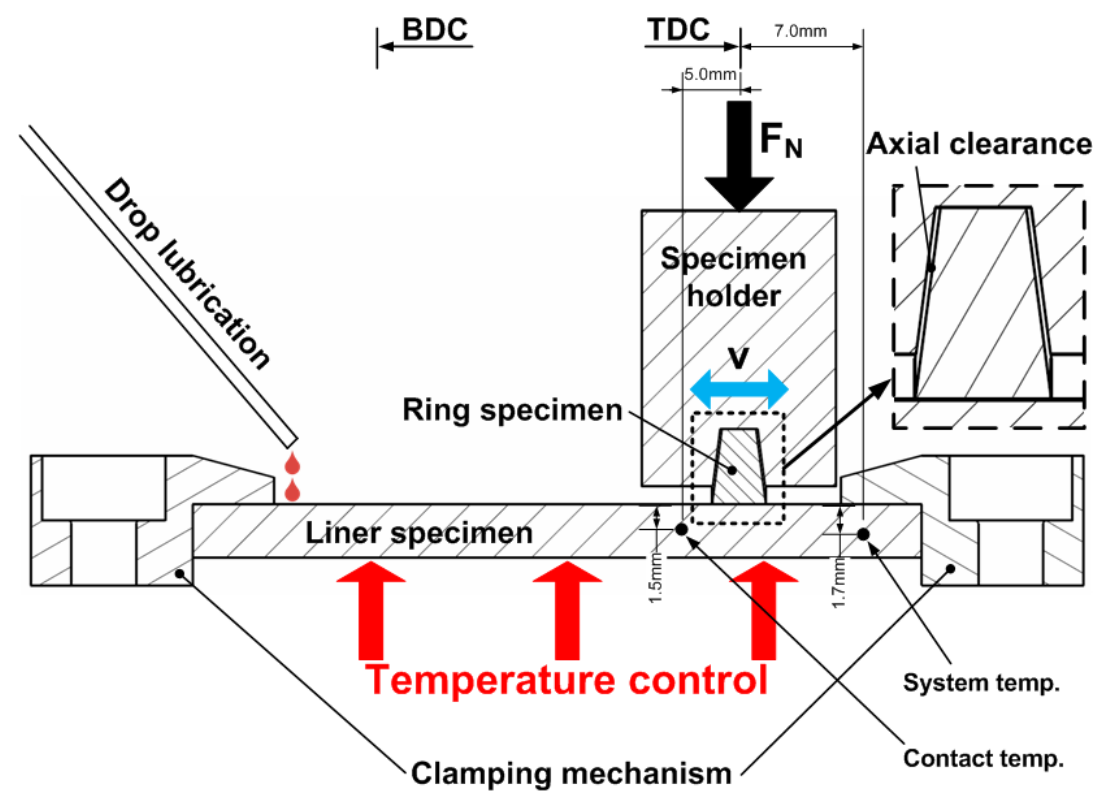

Figure 2. Set-up of the test rig.

As a result of the operating principle of the piston ring, sealing the combustion chamber with the support of the gas pressure (up to 180 bar according to [23]), the contact pressure of the tribosystem ring/liner is dependent on the operating mode and crank angle. On the basis of measured pressure traces of a heavy-duty diesel engine [25], a mean pressure of $\approx 4.5 \mathrm{MPa}$ was calculated. Assuming the harshest conditions with the maximum gas pressure acting on the piston ring, a constant pressure according to the projected area of $5 \mathrm{MPa}$ was chosen for the running-in phase.

\subsection{Test Configuration}

A linear tribometer TE77, manufactured by Phoenix Tribology (details can be found in $[8,26]$ ), was used to generate the reciprocal motion of a piston ring specimen on a stationary cylinder liner specimen (see Figure 1). Ring specimens were machined out of the original piston top-rings, whereby the useable ring parts were detected using a pressure sensitive foil FUJIFILM PRESCALE. Ring segments near the free gap showed the best geometrical conformity to the liner radius. Initial testing of the set-up was carried out with rings with the top coating removed, in order to mimic running-in and normal wear.

For the liner specimen production, an original HDD grey cast engine liner was machined to an equal wall thickness of $3.3 \mathrm{~mm}$. This action gave us the opportunity to cut a high number of equal specimens out of one liner and additionally improve the heating capability of the system. The contact width was $7 \mathrm{~mm}$.

Both specimens were placed in specially designed fixtures on the TE77 (see Figure 2). The liner specimen was mounted in an oil containment unit, which sat right on top of an electrical heating plate. The ring specimen was placed in the movable specimen holder, which represents a piston ring 
groove. During the design process, special attention was paid to ensure the possibility of the ring specimen to perform secondary movements similar to the engine parts. Therefore, the ring groove was designed with an axial clearance the same as in the engine to ensure similar phenomena, such as ring twisting. Furthermore, the ring specimen was able to move sideways to recreate phenomena such as ring turning. To ensure correct alignment, the pressure distribution between the contact partners was checked in the mounted position, using the pressure sensitive foil FUJIFILM PRESCALE.

The drop lubrication of the contact was performed with a peristaltic pump, with a flow rate of $0.04 \mathrm{~mL} / \mathrm{min}$ of fresh oil. Using a precisely positioned medical injection needle, this low oil amount was fed onto the liner at a distance of $\approx 1.5 \mathrm{~mm}$ to the reversal point of the ring, which is named BDC (bottom dead centre). To ensure a continuous and reliable lubrication situation, the tribometer was tilted at an angle of $4^{\circ}$ so that BDC was elevated. Liner and ring specimens were mounted in a way that their bottom sides pointed towards BDC— the oil injection side. Oil removal was carried out by a drain line in the oil containment unit at the lower lying TDC (top dead centre). The temperature was controlled with the system temperature as reference, measured with a thermocouple next to the contact area to avoid the influence of frictional heating. For a qualitative acquisition of the contact temperature, a thermocouple was placed $1.5 \mathrm{~mm}$ underneath the TDC running surface of the liner specimen. All tests were carried out with a stroke of $24.7 \mathrm{~mm}$.

Beside the acquisition of the input parameter, such as system temperature, motion frequency and normal load, additional output parameters were recorded. These were the friction force for the calculation of the friction coefficient, contact temperature and an electrical resistance measurement of the contact, named contact potential. A value of $50 \mathrm{mV}$ represents electrical isolation of the contact, whereby $0 \mathrm{mV}$ indicates metallic contact (a more detailed description can be found in $[3,27]$ ). All parameters were recorded as $0.1 \mathrm{~s}$ averaged values. For friction force, contact potential and stroke, a $1 \mathrm{kHz}$ high-speed data acquisition was also available.

Gravimetric wear was evaluated by a weight measurement of the specimens before and after the tests, using a Sartorius CP 225 D-OCE with a precision of $0.01 \mathrm{mg}$. Before every weighing, the specimens were cleaned with Iso-2-propanol.

\subsection{Test Strategy}

The tests were carried out at a constant system temperature of $160^{\circ} \mathrm{C}$. The system was heated to temperature while a $5 \mathrm{~Hz}$ motion frequency was applied, to ensure a uniform lubrication and heating situation. To create a seizure event, the normal force was increased stepwise, after a running-in phase (see Figure 3). The motion frequency during the running-in phase was $10 \mathrm{~Hz}$, followed by a stepwise increase of the frequency to a maximum of $20 \mathrm{~Hz}$. In [28], they showed that increasing frequency increases the probability of a seizure event. Using this fact enables the seizure testing of the model system in a reasonable time frame and normal load range. After the normal running-in pressure of $5 \mathrm{MPa}$ (applied on the projected contact area), the pressure was increased $2.5 \mathrm{MPa}$ every $20 \mathrm{~min}$ until it reached $42.5 \mathrm{MPa}$, which was limited by the maximum normal force of the machine. With the test-stop-criteria of a friction coefficient higher than 0.2 , we were able to stop the test within single strokes after seizure occured. 


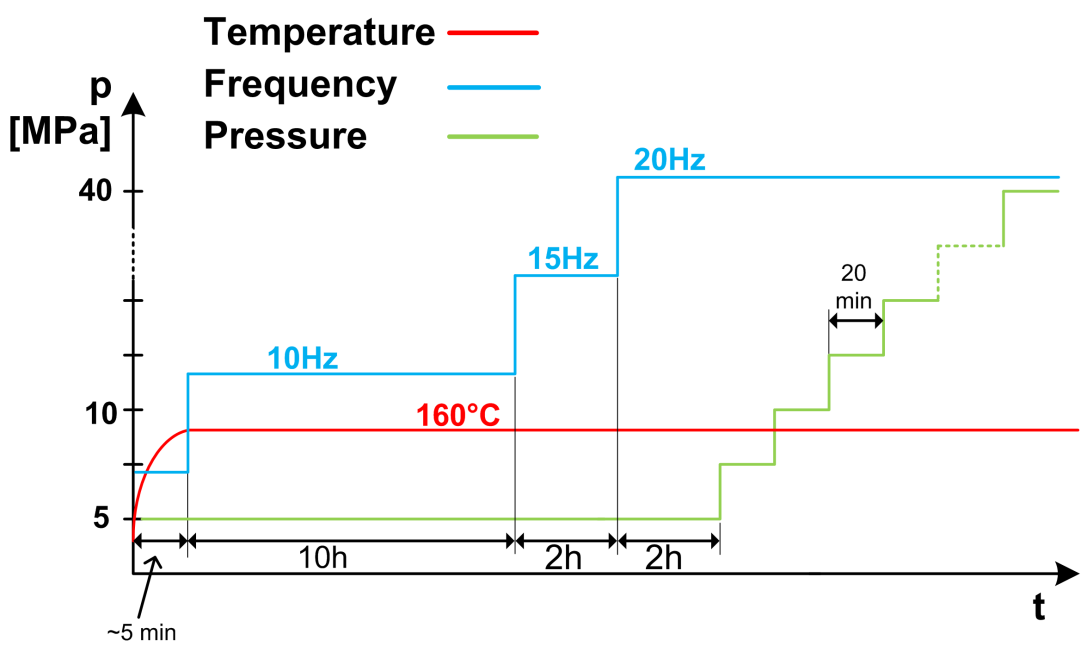

Figure 3. Test strategy.

\section{Validation}

To validate the quality of the model test system in terms of transferability of results to a real engine, parts from scuffed engines were made available. Furthermore, two oils with different (but known) scuffing resistances in the engine were used for these validation tests. "Oil 1", in contrast to "Oil 2", is known for having a poorer scuffing performance. Both engine oils have a similar viscosity grade (5W-30) and phosphorus level (800 ppm).

\subsection{Test Results}

With the presented methodology, a clear and reproducible separation of the seizure limits, in accordance to the known scuffing performance, was obtained. Figures 4 and 5 show two representative tests with "Oil 1". For both runs, the test aborted at a normal pressure of $27.5 \mathrm{MPa}$. A similar behaviour regarding the output parameters, such as coefficient of friction (COF) and contact temperature, over test time can be observed.
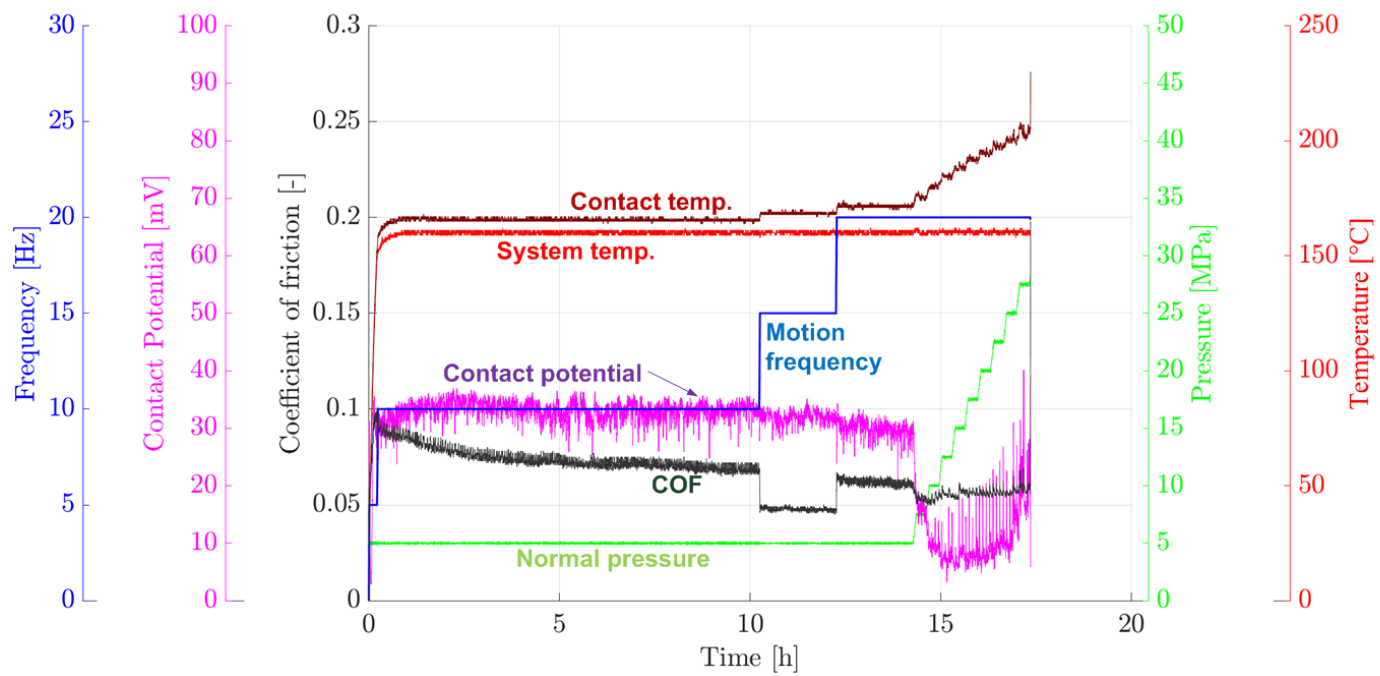

Figure 4. “Oil 1", Test Nr. 1.

During the running-in phase, a decreasing COF can be observed. Contact temperature and contact potential stay stable. When the speed increases to $15 \mathrm{~Hz}$, a drop in COF together with a rise in the contact temperature takes place. The temperature increase also happens for the $20 \mathrm{~Hz}$ step, but the COF shows a sudden increase to approximately 0.07. During the frequency steps, the contact 
potential stays stable, until the load step phase starts. This test phase is marked by a significant contact temperature rise, a fairly constant $\mathrm{COF}$ and a strong fluctuating contact potential signal. The tests stop with a sudden seizure event, showing a COF and a contact temperature peak.
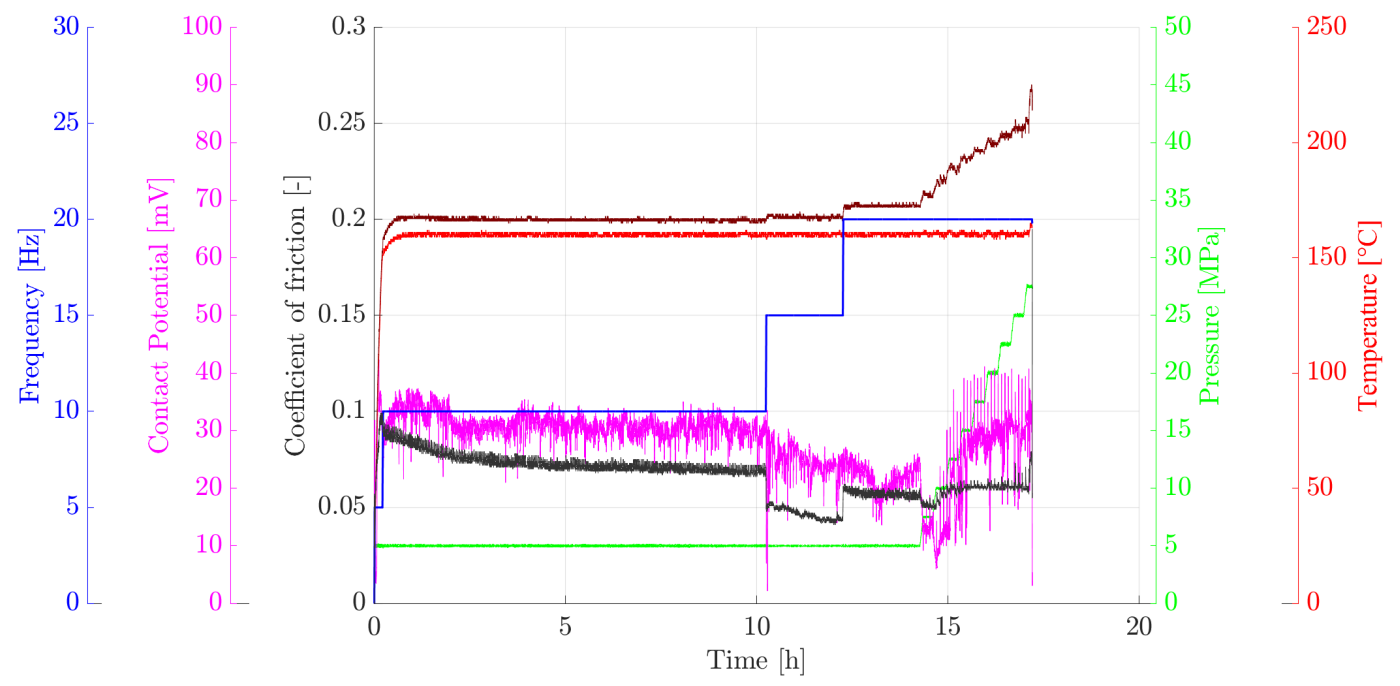

Figure 5. “Oil 1", Test Nr. 2.

"Oil 2" was also run as a comparison to the highly reproducible results from "Oil 1" (see Figure 6). Similar basic phenomena can be observed, such as the COF drop during the $15 \mathrm{~Hz}$ step and the increasing frictional heating with increasing frequency and normal load. After starting the stepwise load increase, the contact potential becomes unstable. A slight downward trend of the COF can be seen. However, the peaks of the COF are more significant and seem to correlate to the fluctuations of the contact temperature and the contact potential. Finally, the test seizures at the load step of $42.5 \mathrm{MPa}$, which is significantly higher than the final load steps of "Oil 1" and corresponds to the known engine performance.
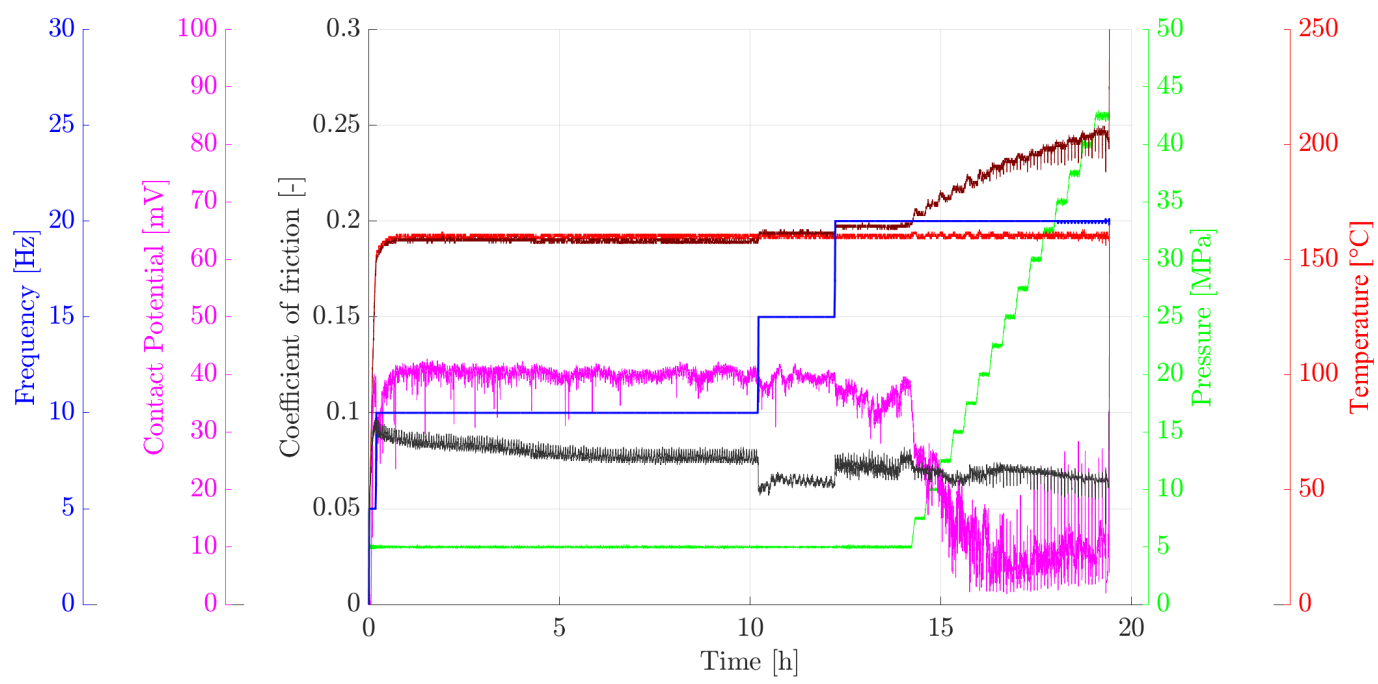

Figure 6. “Oil 2", Test Nr. 1.

Representative of all performed tests, Figure 7 shows a detailed snapshot of the 0.1 s-averaged data before the seizure event of Test Nr. 1 for "Oil 1". At around $10 \mathrm{~s}$ before the test shutdown, a slowly increasing COF can be observed. The other output parameters, like contact temperature and contact potential, become unstable approximately $5 \mathrm{~s}$ before the test shutdown. From this point on, 
the COF increases until the final shutdown criteria of 0.2 is achieved. Therefore, seizure appears to be a process of several seconds and has to run through different stages, like slow-initial and final-rapid COF increase.

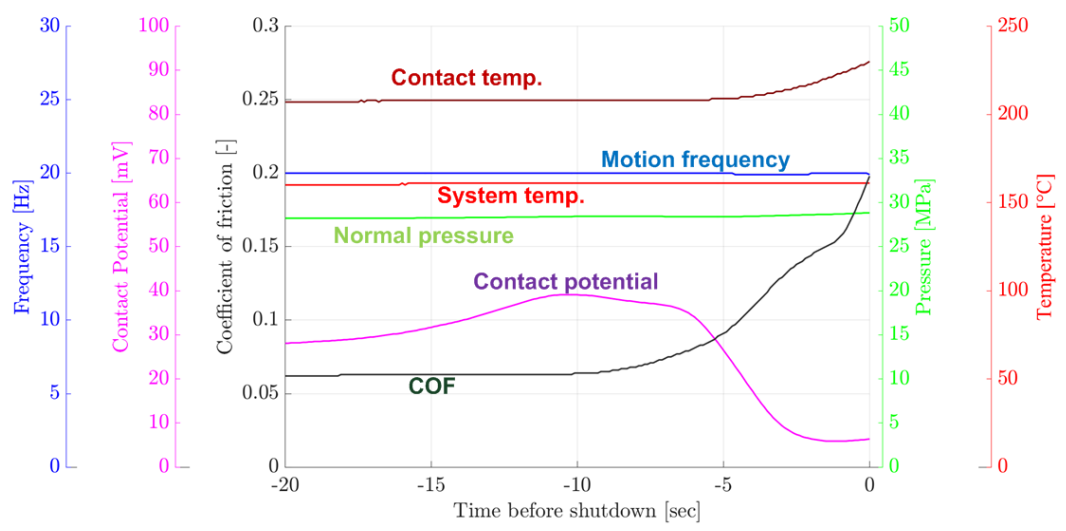

Figure 7. Detailed test graph right before the test shutdown of "Oil 1", Test Nr. 1.

With the analysis of the $1 \mathrm{kHz}$ high-speed data acquisition, we are able to get a closer look at the COF drop during the $15 \mathrm{~Hz}$ step. High speed COF data of the $10 \mathrm{~Hz}, 15 \mathrm{~Hz}$ and $20 \mathrm{~Hz}$ step of Test Nr. 2 of "Oil 1" is plotted over the corresponding stroke, in Figure 8. All signals are recorded for $5 \mathrm{~s}$ (so 5000 measurement points) at the end of each frequency step. Contact pressure was constant at $5 \mathrm{MPa}$.

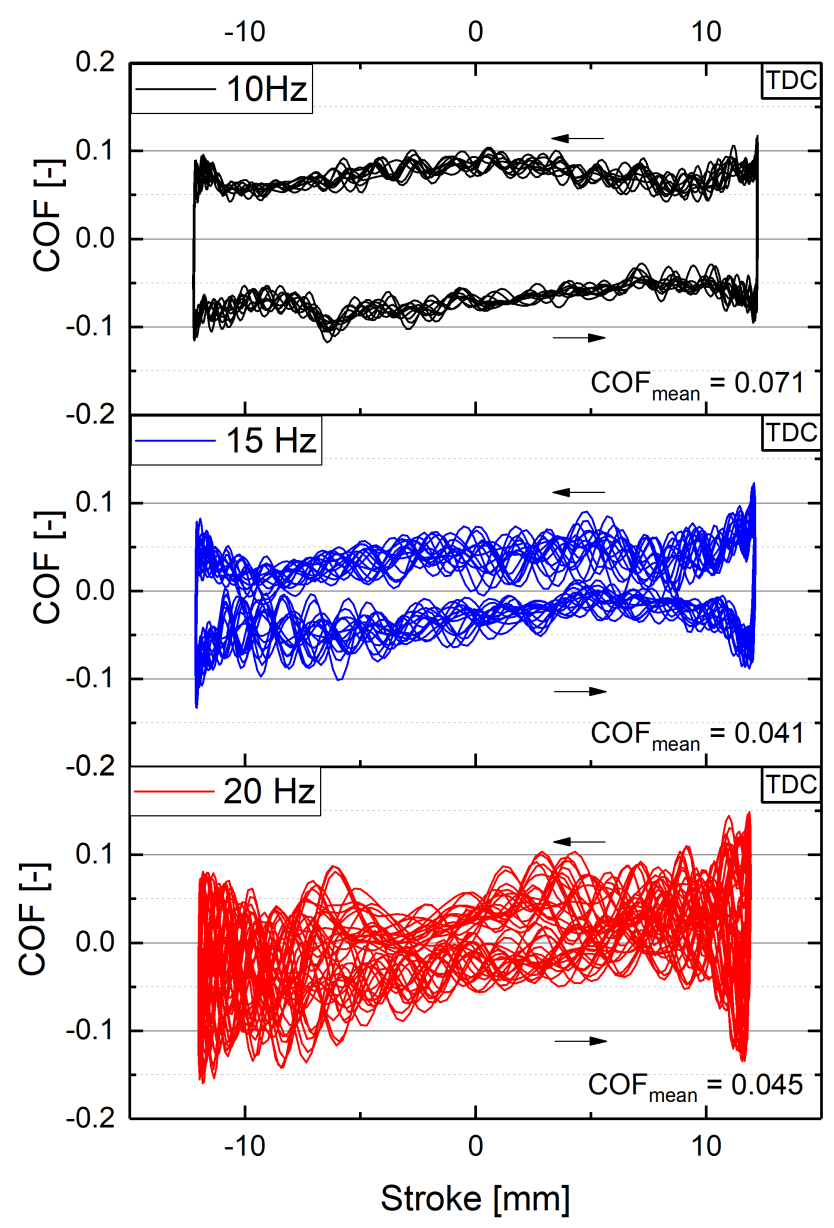

Figure 8. High-speed data at various motion frequencies. 
The signal of change of COF at the dead centres is very visible for all frequency plots (TDC is located on the right side; arrows indicate the direction of motion). For $10 \mathrm{~Hz}$ there is no significant reduction in friction in the area of maximum speed $($ Stroke $=0 \mathrm{~mm}$ ) due to hydrodynamic fluid friction. The mean COF for the plotted test data is calculated by the integration of the absolute values of the 5000 measurement points:

$$
\mathrm{COF}_{\text {mean }}=\frac{1}{5000} \int_{n=1}^{n=5000}|\operatorname{COF}(n)| d n .
$$

For $10 \mathrm{~Hz}$, a mean COF of 0.071 was calculated, which is in the range of the $10 \mathrm{~Hz}$ low-speed data acquisition.

At $15 \mathrm{~Hz}$, a more obvious COF reduction during motion, in relation to the dead centre positions, can be observed. Fluctuations increase for the more hydrodynamic friction regime, whereby friction at the dead centres stays in the same range. Furthermore, a higher static friction for the starting points of motion produce a slight twist of the hysteresis. The calculated mean COF is 0.041 which is lower than $\approx 0.045$ of the low-speed data acquisition.

The $20 \mathrm{~Hz}$ frequency shows high fluctuations and a more pronounced hydrodynamic friction reduction. However, in contrast to the slower frequency phases, static friction at the dead centres seems to be higher, especially at the starting points of motion. The twist of the hysteresis, found for the $15 \mathrm{~Hz}$ phase, can be also seen for $20 \mathrm{~Hz}$. The calculation of the mean COF for the plotted data gives 0.045 , which is below the low-speed COF data of $\approx 0.06$. The reasons for this could be that the low-speed data acquisition cannot record the fluctuations, which obviously significantly reduce the mean COF.

Looking at the gravimetric wear data reveals that for all tests, the liner specimens lost weight, while the ring specimens gained weight (see results in Table 2). This indicates a transfer of material, which can be traced back to a pull-out from the liner surface and adhesion to the ring surface.

Table 2. Gravimetric wear results.

\begin{tabular}{ccc}
\hline Test-ID & Liner Weight Change (mg) & Ring Weight Change (mg) \\
\hline “Oil 1", Test Nr. 1 & -8.08 & 0.73 \\
"Oil 1", Test Nr. 2 & -8.22 & 0.67 \\
“Oil 2", Test Nr. 1 & -12.61 & 1.20 \\
\hline
\end{tabular}

\subsection{Surface Analysis}

Surface analysis shows similar damage mechanisms taking place in both the model system and the engine. A scuffed engine liner (Figure 9) shows a scuffed surface with heavy adhesive wear and a black piston seizure mark. Some of the initial honing surface outside the running area of the piston rig can also be seen. The obviously pulled out, deformed and mixed material is flattened from several piston ring transits, until the engine was shut down.

On the model specimen (Figure 10), a similar adhesive-damaged surface can be found in the centric seizure mark. Remarkably, the surface is still very rough, which is due to the rapid stop of the tribometer upon a friction peak and the occurrence of a seizure. Beside the seizure mark, the liner specimen is covered with tribo pads, which can be explained by the use of fresh oil without soot for the model $[29,30]$. Near the dead centres of the specimen, small microseizure marks are visible. These indicate the critical contact conditions in the area near the dead centres. Subsequently, one can assume that the origin of the macroscopic seizure event is also located in that area, where relative motion is too low for sufficient hydrodynamic support. Scanning electron microscope images of engine parts and model specimen were recorded at $7.5 \mathrm{kV}$ acceleration voltage. 


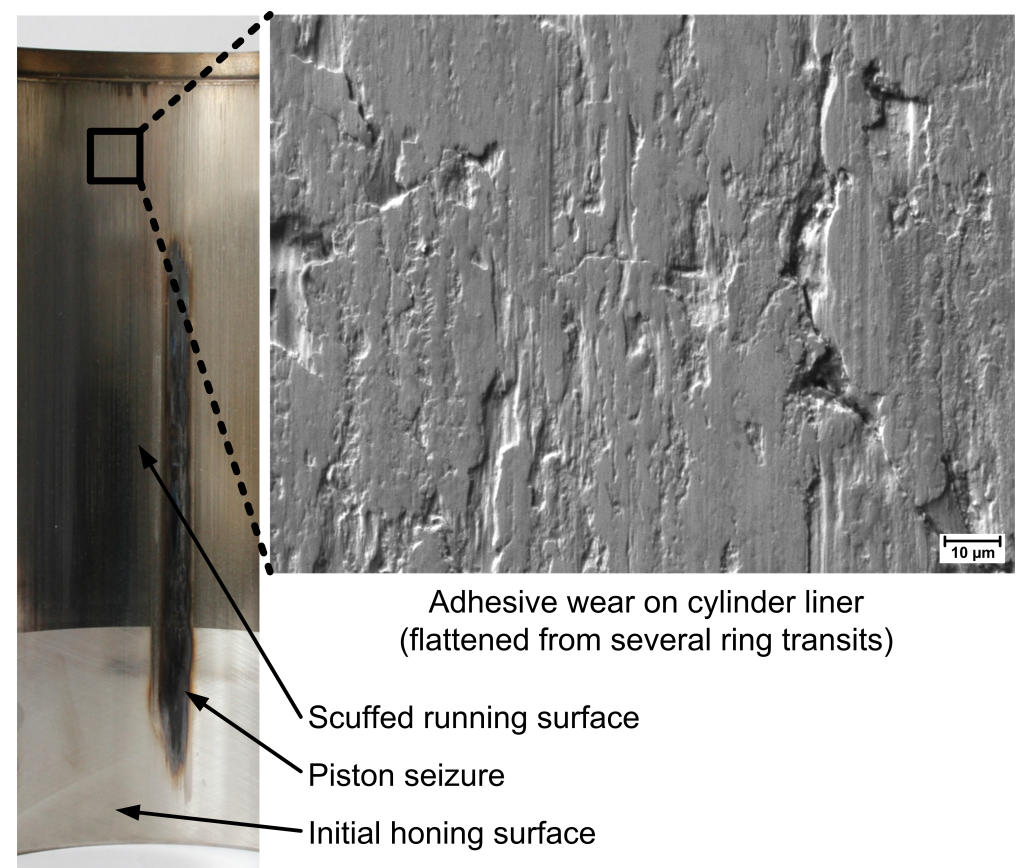

Figure 9. Liner surface analysis—engine part.

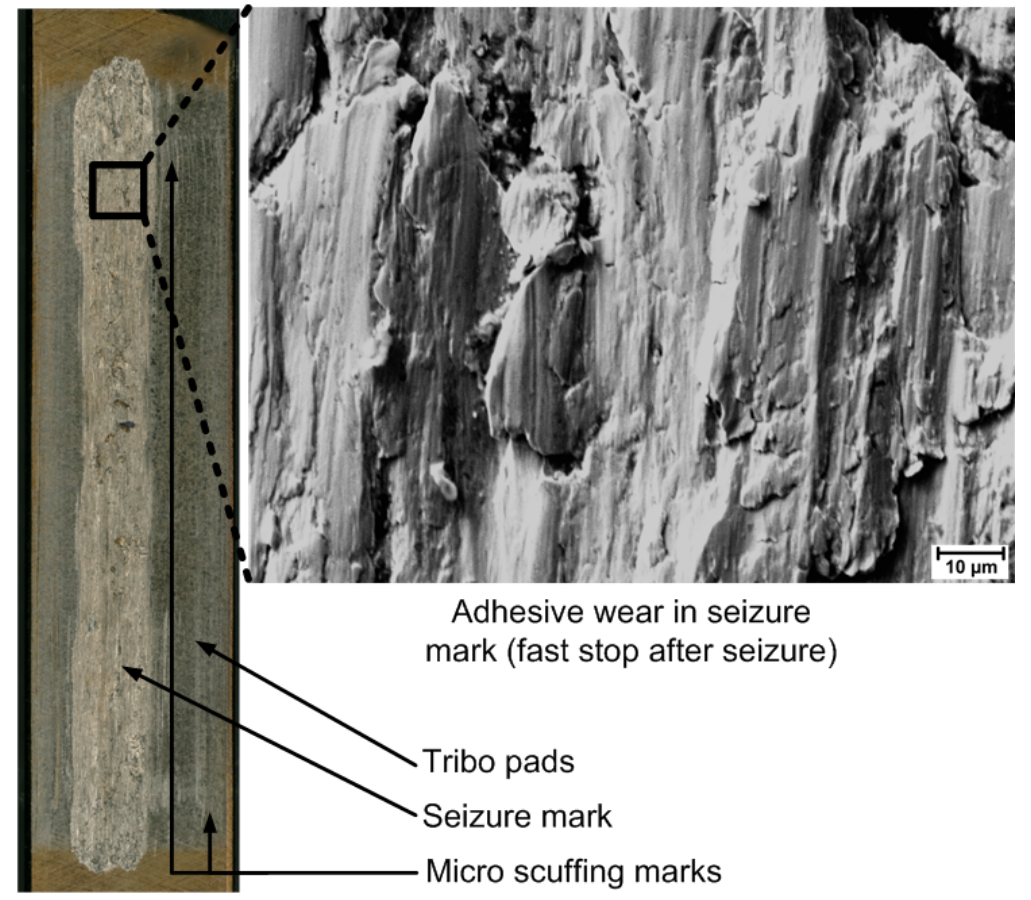

Figure 10. Liner surface analysis—model specimen.

A look at the ring surface of the finished test model (Figure 11) shows a massive material transfer from the liner onto the ring. Beside the seizure mark, tribo pads cover the primary sliding contact area of the ring specimen. This primary sliding contact area is located right at the centre of the crowned piston ring contact geometry. Towards the bottom and the top side, small microscuffing marks can be detected. These may correlate with the microseizure marks found on the liner specimen near the dead centres. The areas on the piston ring that were not in contact show machining marks in the peripheral direction. 


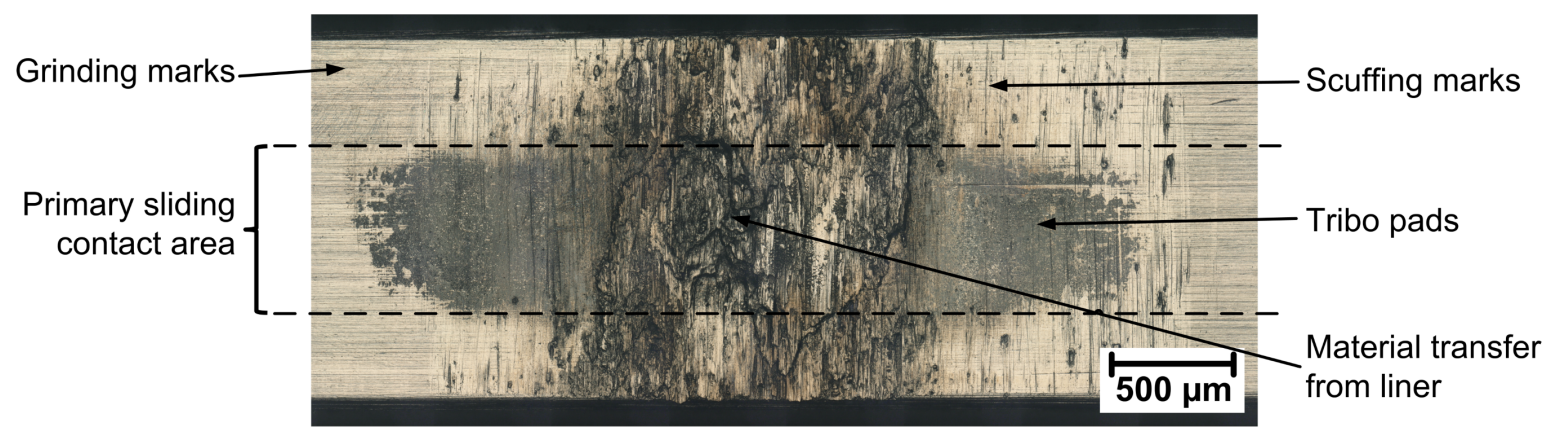

Figure 11. Ring specimen—surface analysis.

\section{Discussion}

One can compare the presented damage and failure mechanisms with the reported surface analysis from the failed engine components. Greuter and Zima show in [31] similar running patterns for liners and piston rings of diesel engines. Shuster et al. also observed a material transfer from the cast-iron liners onto coated piston rings from field engines [32]. Comparing the experimental investigations by Kamps et al. and Tas et al. $[33,34]$ indicates similar observations of a material transfer from the liner onto the ring. In addition, Saeidi et al. describe a hypothesis for the origin of this macroscopic seizure event by local metal-metal contact and the subsequent input of shear stresses [35]. This may result in a local fracture and adhesive removal of the liner material particles. The observed microseizure marks on the liner near the dead centres and the correlating seizure marks on the ring may indicate the accuracy of these theories. However, additional analyses have to be carried out to sufficiently investigate the origin and the detailed evolution of scuffing of piston ring/cylinder liner-contacts in combustion engines.

\section{Conclusions}

The presented laboratory testing methodology visualises the characteristic tribological effects of the piston ring/cylinder liner-contact correlating to the engine. Wear mechanisms and tribosystem ranking match the failure analysis and empirical values from a comparable diesel engine. Beside the opportunity to provide a tool for the scientific community and for the industry to gain a basic understanding of the tribological behaviour of the piston ring/cylinder liner-contact outside the engine, a deeper insight into the evolution of the scuffing process was also achieved. In accordance with the fundamental literature, the surface analysis shows an adhesive-forced material transfer from the liner onto the piston ring. Furthermore, damage analyses of the specimens indicate similar findings as regards the origin of the scuffing event, which is in agreement with the relevant literature.

Author Contributions: Data curation, M.P.; Investigation, M.P.; Methodology, M.P. and D.W.; Supervision, F.S. and F.G.; Writing—original draft, M.P.; Writing—review \& editing, F.S., D.W. and F.G.

Funding: This research received no external funding.

Conflicts of Interest: The authors declare no conflict of interest.

\section{References}

1. Hackländer, A. Engine Oils for Vehicles_Current Trends and Oil Analysis; Oelcheck Technology Focus: Brannenburg, Germany, 2018; pp. 4-5.

2. Infineum Insight. How Low Will Viscosity Go? Infineum International Limited: Abingdon, UK, 2012.

3. Johansson, S.; Nilsson, P.H.; Ohlsson, R.; Rosén, B.G. Experimental friction evaluation of cylinder liner/piston ring contact. Wear 2011, 271, 625-633. [CrossRef]

4. Grabon, W.; Koszela, W.; Pawlus, P.; Ochwat, S. Improving tribological behaviour of piston ring-cylinder liner frictional pair by liner surface texturing. Tribol. Int. 2013, 61, 102-108. [CrossRef] 
5. Schiffer, J.; Krampl, H.; Godor, I.; Grün, F.; Betz, M.; Laiminger, S. Optimization of the piston ring-cylinder linersystem in gas-engines for power generation. In Proceedings of the 27th CIMAC World Congress on Combustion Engine Technology, Shanghai, China, 13-16 May 2013.

6. Obert, P.; Müller, T.; Füßer, H.J.; Bartel, D. The influence of oil supply and cylinder liner temperature on friction, wear and scuffing behavior of piston ring cylinder liner contacts-A new model test. Tribol. Int. 2016, 94, 306-314. [CrossRef]

7. Olander, P.; Jacobson, S. Scuffing resistance testing of piston ring materials for marine two-stroke diesel engines and mapping of the operating mechanisms. Wear 2015, 330-331, 42-48. [CrossRef]

8. Kamps, T.J.; Walker, J.C.; Wood, R.J.; Lee, P.M.; Plint, A.G. Reproducing automotive engine scuffing using a lubricated reciprocating contact. Wear 2015, 332-333, 1193-1199. [CrossRef]

9. Keller, J.; Fridrici, V.; Kapsa, P.; Huard, J.F. Surface topography and tribology of cast iron in boundary lubrication. Tribol. Int. 2009, 42, 1011-1018. [CrossRef]

10. Pusterhofer, M.; Summer, F.; Maier, M.; Grün, F. Assessment of shaft surface structures on the tribological behavior of journal bearings by physical and virtual simulation. Lubricants 2019, submitted.

11. Grabon, W.; Pawlus, P.; Sep, J. Tribological characteristics of one-process and two-process cylinder liner honed surfaces under reciprocating sliding conditions. Tribol. Int. 2010, 43, 1882-1892. [CrossRef]

12. Liu, K.; Liu, X.J.; Gui, C.L. Scuffing failure analysis and experimental simulation of piston ring-cylinder liner. Tribol. Lett. 1998, 5, 309-312. [CrossRef]

13. Shuster, M.; Combs, D.; Karrip, K.; Burke, D. Piston Ring Cylinder Liner Scuffing Phenomenon Studies Using Acoustic Emission Technique; SAE International: Warrendale, PA, USA, 2000.

14. Söderfjäll, M.; Herbst, H.M.; Larsson, R.; Almqvist, A. Influence on friction from piston ring design, cylinder liner roughness and lubricant properties. Tribol. Int. 2017, 116, 272-284. [CrossRef]

15. Wopelka, T.; Cihak-Bayr, U.; Lenauer, C.; Ditrói, F.; Takács, S.; Sequard-Base, J.; Jech, M. Wear of different material pairings for the cylinder liner-piston ring contact. Ind. Lubr. Tribol. 2018, 70, 687-699. [CrossRef]

16. Olander, P.; Eskildsen, S.S.; Fogh, J.W.; Hollman, P.; Jacobson, S. Testing scuffing resistance of materials for marine 2-stroke engines-Difficulties with lab scale testing of a complex phenomenon. Wear 2015, 340-341, 9-18. [CrossRef]

17. Truhan, J.J.; Qu, J.; Blau, P.J. A rig test to measure friction and wear of heavy duty diesel engine piston rings and cylinder liners using realistic lubricants. Tribol. Int. 2005, 38, 211-218. [CrossRef]

18. Biberger, J.; Füßer, H.J. Development of a test method for a realistic, single parameter-dependent analysis of piston ring versus cylinder liner contacts with a rotational tribometer. Tribol. Int. 2017, 113, 111-124. [CrossRef]

19. Neale, M.J. Piston ring scuffing-A broad survey of problems and practice. Proc. Inst. Mech. Eng. 1970, 21-32. [CrossRef]

20. Balyts'kyi, O.I.; Abramek, K.F.; Shtoeck, T.; Osipowicz, T. Diagnostics of Degradation of the Lock of a Sealing Ring According to the Loss of Working Gases of an Internal Combustion Engine. Mater. Sci. 2014, 50, 156-159. [CrossRef]

21. Balyts'kyi, O.I.; Abramek, K.F.; Mruzik, M.; Stoeck, T.; Osipowicz, T. Evaluation of the Losses of Hydrogen-Containing Gases in the Process of Wear of Pistons of an Internal-Combustion Engine. Mater. Sci. 2017, 53, 289-294. [CrossRef]

22. MAHLE GmbH (Ed.) Kolben und Motorische Erprobung, 2nd ed.; Springer: Wiesbaden, Germany, 2015.

23. Zima, S. Motorkolben: Bauarten, Betrieb, Schäden, 1st ed.; Vieweg \& Sohn Verlag: Wiesbaden, Germany, 2005.

24. van Basshuysen, R.; Schäfer, F. (Eds.) Handbuch Verbrennungsmotor: Grundlagen, Komponenten, Systeme, Perspektiven, 8th ed.; Springer: Wiesbaden, Germany, 2017.

25. Salehi, R.; Stefanopoulou, A. Cylinder Pressure Data from a Heavy Duty Diesel Engine; University of Michigan: Ann Arbor, MI, USA, 2015.

26. Schiffer, J.; Gódor, I.; Grün, F.; Eichlseder, W. A Model Scale Test Method for the Piston Ring-Cylinder Liner Tribosystem of Internal Combustion Engines. Arch. Mech. Eng. 2010, 57, 211. [CrossRef]

27. Summer, F.; Grün, F.; Schiffer, J.; Gódor, I.; Papadimitriou, I. Tribological study of crankshaft bearing systems: Comparison of forged steel and cast iron counterparts under start-stop operation. Wear 2015, 338-339, 232-241. [CrossRef]

28. Galligan, J.; Torrance, A.A.; Liraut, G. A scuffing test for piston ring/bore combinations: Pt. II. Formulated motor lubrication. Wear 1999, 236, 210-220. [CrossRef] 
29. Kontou, A.; Southby, M.; Spikes, H.A. Effect of steel hardness on soot wear. Wear 2017, 390-391, $236-245$. [CrossRef]

30. Motamen Salehi, F.; Morina, A.; Neville, A. The effect of soot and diesel contamination on wear and friction of engine oil pump. Tribol. Int. 2017, 115, 285-296. [CrossRef]

31. Greuter, E.; Zima, S. Motorschäden: Schäden an Verbrennungsmotoren und Deren Ursachen; Vogel: Würzburg, Germany, 2000.

32. Shuster, M.; Stong, T.; Deis, M.; Burke, D. Piston Ring Cylinder Liner Scuffing Phenomenon: Investigation, Simulation and Prevention; SAE Technical Paper; SAE International: Warrendale, PA, USA, 1999.

33. Kamps, T.J.; Walker, J.C.; Wood, R.J.; Lee, P.M.; Plint, A.G. Scuffing mechanisms of EN-GJS 400-15 spheroidal graphite cast iron against a 52100 bearing steel in a PAO lubricated reciprocating contact. Wear 2017, 376-377, 1542-1551. [CrossRef]

34. Tas, M.O.; Banerji, A.; Lou, M.; Lukitsch, M.J.; Alpas, A.T. Roles of mirror-like surface finish and DLC coated piston rings on increasing scuffing resistance of cast iron cylinder liners. Wear 2017, 376-377, 1558-1569. [CrossRef]

35. Saeidi, F.; Taylor, A.A.; Meylan, B.; Hoffmann, P.; Wasmer, K. Origin of scuffing in grey cast iron-steel tribo-system. Mater. Des. 2017, 116, 622-630. [CrossRef]

(C) 2019 by the authors. Licensee MDPI, Basel, Switzerland. This article is an open access article distributed under the terms and conditions of the Creative Commons Attribution (CC BY) license (http:/ / creativecommons.org/licenses/by/4.0/). 